\title{
THE RELATIONSHIP BETWEEN BODY MASS INDEX AND SEMEN QUALITY AND SEX HORMONES AMONG INFERTILE MEN
}

\author{
${ }^{1}$ Katayon Berjis, ${ }^{2 *}$ Azra Azmodeh, ${ }^{3}$ Nasser Salsabili, ${ }^{4}$ Ebrahim Mostafavi, ${ }^{5}$ Mansoureh Moaya, \\ ${ }^{6}$ Mahdieh Sadat Ghiasi, ${ }^{7}$ Sahar Farzaneh
}

\author{
${ }^{1}$ Department of Mirza-koochak- khan infertility center, Tehran University, Tehran, Iran. \\ ${ }^{2}$ Department of Tehran university of Medical Sciences, Fellowship of infertility Mirza-koochak- \\ khan infertility center, Tehran University, Tehran, Iran. \\ ${ }^{3}$ Dept. of IVF, Mirza Koochak Khan Hospital, School of Rehabilitation, \\ Tehran University of Medical Sciences, Tehran, Iran. \\ ${ }^{4} \mathrm{PhD}$., Assistant Professor, Biochemist, Department of Obstetrics and Gynecology, \\ Tehran University of Medical Sciences, Tehran, Iran. \\ ${ }^{5}$ Obstetrics and Gynecology Department, Azad University of Medical Sciences, Tehran, Iran. \\ ${ }^{6}$ Iranian Tissue Bank and Research Center, Tehran. University Of Medical Sciences,Tehran, Iran. \\ ${ }^{7}$ Department of biology, Parand Branch, Islamic Azad University, Parand, Iran.
}

*Corresponding author

DOI: https://doi.org/10.51193/IJETSI.2021.6401

\begin{abstract}
Obesity decreases fertility in women. There are some reports in case of semen quality disorder in men with increasing weight. With regard to the effect of weight gain in decreasing fertility we decided to investigate the relation of body mass index with semen parameters and sex hormones. We grouped 550 infertile men between 20-45 years old based on calculated BMI values (normal, 19 to $24 \mathrm{~kg} / \mathrm{m} 2$, overweight, $24 / 1$ to 29 , obese > 29/1). Clinical examinations and BMI calculation by measuring weight and height, semen analysis, and blood serology were done for all patients. There were significant differences between semen parameters and BMI in three groups. Body mass index was negatively correlated with total sperm count, motility and morphology. In comparison between sex hormones with sperm count positive meaningful statistical relation with LH, FSH and estradiol and negative meaningful statistical relation with testosterone were observed. With regard to these results we concluded that body mass index
\end{abstract}


more than 24 had reverse relation with sperm count. Therefore, we suggest to decrease weight and prescribe a diet are important in men with low fertility due to semen quality disorder.

Keywords: BMI, Blood serology, Semen index.

\section{INTRODUCTION}

Obesity is introduced as an epidemic problem in the whole world (2). The prevalence of obesity in Europe is estimated at 10-20\% of men and 10-25\% of women (1). The relationship between obesity and infertility in men was first described by Avicenna in the 10th century (3). But there isn't complete information about the exact effect of body mass index in semen quality (5). Over weight not only increases chronic diseases following mortality and morbidity but also increases fertility problem (4) both infertility and obesity decrease quality of life among people So many studied indicated the relationship between male obesity and fertility problems that ended to poor pregnancy outcome . Positive relations have been reported between male factors infertility and metabolic syndrome. Finally, it has been shown obese couple are less fertile than those with normal body mass index. Only recently in the last 2-3 year the impact of an obese male partner on embryo development and pregnancy been assessed (6). In a study in 2008 with 520 men inverse effect between sperm count and its mobility with body mass index have been found $(7$, 8 ). There are several studies that have investigated the impact of male obesity on the traditional sperm parameters mandated by the world health organization (WHO), that is sperm concentration, sperm motility and sperm morphology (6). Also a Positive relation between the percent of sperm DNA fragmentation and high BMI was found. Hilton (9-11) here is some evidence that male obesity reduces sperm concentration that was reported by 15 out of 23 recent studies. There was another study at which the unpleasant effect of obesity on erectile dysfunction and sperm parameters were emphasized. Ahmad, Settle, Chung (12-14). Obesity in men is almost accompanied with hormonal disorders and infertility problems. Several studies documented that increased male BMI is associated with reduced plasma concentrations of SHBG and therefore free and total testosterone and increased plasma concentration of estrogen (6). There are various reports showing that fat accumulation in men consequence decrease of free and total testosterone and increase of serum estradiol level and these two changes can lead to a general decrease in sperm counts (15). The answer of this questions how obesity results infertility in men can be multifactorial. As we known Obesity leads to a kind of hypoandrogenism by increasing the serum estradiol level and decreasing the testosterone level, these affect changes spermatogenesis that can cause low sperm count and then male factor infertility problems With regard to increased obesity especially in civilized societies, over weight and infertility should be more focused $(18,19)$. We cannot found similar studied about body mass index and semen quality inside our country in our researches'. There was not many studied that 


\section{International Journal of Engineering Technology and Scientific Innovation}

ISSN: 2456-1851

Volume: 06, Issue: 04 "July-August 2021"

assess the effect of obesity in semen parameters. The main goal of this study is to investigate the relation between body mass index and semen quality.

\section{MATERIAL AND METHOD}

This study has been done as a Crosse sectional study. Among the infertile men who were the clients of Myrza- koochak- khan male infertility clinic from May 2011 to November 2014. A total of 550 healthy infertile men between 20-45 years old were enrolled in this study. They were couples with at least one year infertility period. All of the men were examined and body mass index was calculated as body weight $(\mathrm{kg})$ divided by height squared $(\mathrm{m} 2)$. Blood sample to evaluate serum testosterone, estradiol, prolactin, FSH, LH, and TSH have been taken and were sent to the laboratory. Hormonal evaluations were made using ELISA techniques. Elisa reader system was used for FSH, LH evaluations with moonblind kite. Elisa reader system was used for Testosterone and estradiol evaluations with DRG kite. Elisa reader system was used for prolactin evaluations with PADTANELM kite. Also by self masturbation semen samples were achieved and after 60 minutes being in 37 centigrade degree were analyzed with 40 empowering microscope for morphology and motility and 10 empowering microscope for sperm count with regard to WHO criteria. Variables included age, BMI, semen parameters and serum hormonals assessment. Exclusion criteria were varicocellectomy, vasovasestomy, alcohol or alcohol abuse ,Smoking, male impotency, hyper prolactinemia, Erectile dysfunction, diabetes Mellitus, thyroid dysfunction and Oligo spermia. Also none of the cases has had chronic drug consumption .In diabetic patient's obesity, retrograde ejaculation and neuropathic disorders of diabetes affect sperm count so it can be as an interventional factor. All cases based on BMI, were divided into three groups: group A: $\mathrm{BMI}=18-24 \mathrm{~kg} / \mathrm{m}^{2}$, group B: $\mathrm{BMI}=24 / 1-29 \mathrm{~kg} / \mathrm{m}^{2}$, and group C: $\mathrm{BMI}>$ $29 / 1 \mathrm{~kg} / \mathrm{m}^{2}$. Financial support has been done by Tehran University of medical science.

Statistical analysis: All data's were assessed in SPSS 15 with ANOVA test and linear regression. Significant value was set at $\alpha<0 / 05$. All $p$ values were two -tailed.

\section{RESULT}

In this study 540 infertile men were analyzed. The mean value of age in group $\mathrm{A}(\mathrm{n}=177)$ : BMI18-24 kg/m² was $32 / 2$ and in groups $\mathrm{B}(\mathrm{n}=182)$ : $\mathrm{BMI}=24 / 1-29 \mathrm{~kg} / \mathrm{m}^{2}$ was $32 / 3$ and in group C $(\mathrm{n}=178)$ : $\mathrm{BMI}>29 \mathrm{~kg} / \mathrm{m}^{2}$ was $33 / 1$. There were no significant differences between ages in three groups. The mean value of BMI in group A was 22/4, in group B, it was 26/3 and in group $\mathrm{C}$ was 31/5. In the assessment of correlation between sex hormones (FSH, LH ,testosterone and estradiol) and BMI in 250 cases, positive correlation between BMI and estradiol $(\mathrm{p}=+0 / 04)$ we observed (Table 1). In the assessment of correlation between semen parameters and BMI, sperm count had meaningful negative statistical relation with $\mathrm{BMI}(\mathrm{P}=$ - 
0/0001). We had negative statistical relation between BMI and morphology $(p=-0 / 002)$ and motility $(\mathrm{p}=-0 / 0001)$ as well the relation between BMI and volume of semen was not significant (Table 2). The mean value of sperm count in group A was 75/8, group B was 58/4 and group C was 59 (Figure 1). Liner regression for assessment of relation between BMI and semen parameters has been done and negative meaningful statistical relation between BMI and sperm count was seen ( $\mathrm{p}=0 / 0001)$ (\% $95 \mathrm{CI}$ :-.04 to -.01). In assessment three groups in ANOVA study significant statistical relation between BMI , sperm count $(\mathrm{p}=0 / 0001)$ and morphology $(\mathrm{p}=$ 0/007) were seen.

Table 1: The relation between BMI with sex hormones (More INF in text)

\begin{tabular}{|c|c|c|c|c|}
\hline Variables & $\mathrm{LH}$ & FSH & Estradiole & Testosterone \\
\hline BMI & $.12 \quad \mathrm{NS}$ & $.58 \quad \mathrm{NS}$ & $+.04 \quad \mathrm{~S}$ & .69 \\
\hline
\end{tabular}

Table 2: The relation between BMI and semen parameters, has shown negative statistical relation with $\mathrm{BMI}(\mathrm{P}=-\mathbf{0} / 0001)$. Also there is negative statistical relation between $\mathrm{BMI}$ and morphology $(p=-0 / 002)$ and motility $(p=-0 / 0001)$.

\begin{tabular}{|c|c|c|c|c|}
\hline Variables & count & morphology & mothitiy & volume \\
\hline BMI & -0.0001 & -0.0001 & -0.0001 & NS \\
\hline
\end{tabular}

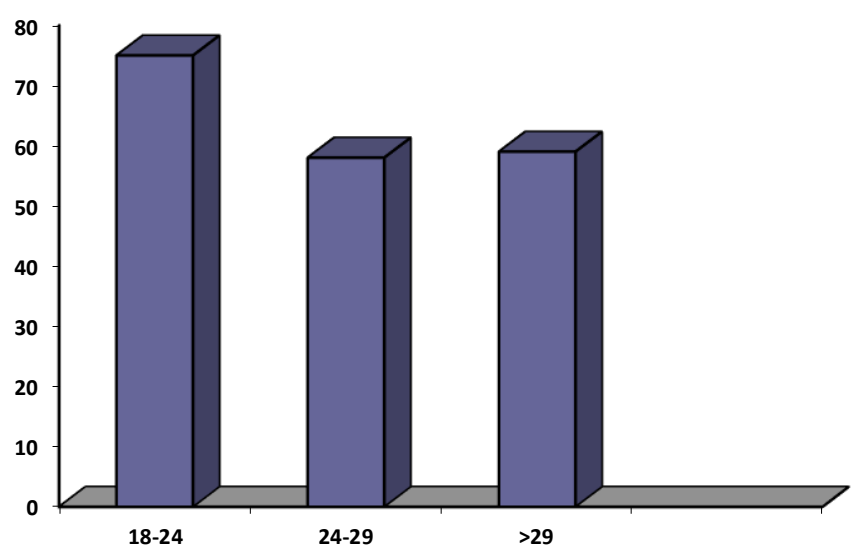

Fig 1: The bar chart has shown the relation between BMI (left) and sperm count (bottom). As we can see The mean value of sperm count in group A $\left(18-24 \mathrm{~kg} / \mathrm{m}^{2}\right)$ was 75/8, group B $\left(24 / 1-29 \mathrm{~kg} / \mathrm{m}^{2}\right)$ was $58 / 4$ and group $\mathrm{C}\left(\mathrm{BMI}>29 \mathrm{~kg} / \mathrm{m}^{2}\right)$ was 59 . 
In assessment between groups with independent sample T-test, The comparison of the two groups A and B showed that the sperm count in group A had a higher rate compared to groups $\mathrm{B}(\mathrm{p}=0 / 0001)$ and comparing morphology of sperm between two groups was meaningful $(\mathrm{P}=$ 0.03). The comparison between groups $\mathrm{A}$ and $\mathrm{C}$, the mean value of sperm count has a higher rate in group $\mathrm{A}(\mathrm{p}=0 / 002)$ and comparing morphology of sperm between two groups showed in group $\mathrm{A}$ morphology of sperm was more than group $\mathrm{C}(\mathrm{p}=0 / 02)$. Both morphology and sperm count decreased with increasing BMI. In contrast two groups $\mathrm{B}$ and $\mathrm{C}$ there were no meaningful statistical difference between sperm count in two groups but comparing morphology of sperm in two groups B and C morphology of sperm in group B had a higher rate compared to group $\mathrm{C}(\mathrm{P}=0.05)($ Table 3$)$.

Table 3: The comparison sperm count between groups with independent samples t-test. (More INF in text)

\begin{tabular}{|c|c|c|}
\hline Groups & mean \pm SD of sperm count & mean \pm SD of morphology \\
\hline A & $75.8 \pm 46.1$ & $32.4 \pm 28.4$ \\
\hline B & $58.4 \pm 42.6$ & $27.8 \pm 26.1$ \\
& $\mathrm{P}=0.0001$ & $\mathrm{P}=0.03$ \\
\hline $\mathrm{A}$ & $75.8 \pm 46.1$ & $32.4 \pm 28.4$ \\
\hline $\mathrm{C}$ & $59 \pm 44.6$ & $24.4 \pm 28.2$ \\
& $\mathrm{P}=0.002$ & $\mathrm{P}=0.02$ \\
\hline $\mathrm{C}$ & $59 \pm 44.6$ & $24.4 \pm 28.2$ \\
\hline $\mathrm{B}$ & $58.4 \pm 42.6$ & $27.8 \pm 26.1$ \\
& $\mathrm{p}=\mathrm{NS}$ & $\mathrm{P}=0.05$ \\
\hline
\end{tabular}


International Journal of Engineering Technology and Scientific Innovation

ISSN: 2456-1851

Volume: 06, Issue: 04 "July-August 2021"

\section{DISCUSSION}

Obesity has been known as a rapidly increasing problem in the world $(1,2)$. Overweight was considered for a neglected male infertility factor. In our study we observed a relationship between morphology, motility and sperm count with BMI. All parameters of sperm decreased with increasing BMI .In Meeker and colleagues study for 388 sperm sample LH and FSH had negatively statistical relation with motility, morphology and sperm count. Finally Meeker and colleagues had found positive statistical relation between testosterone level and sperm motility (15). In the other study by Gopalkrishnan and colleagues in Danish a relation between high BMI and low quality of sperm in infertile men were seen .So prevention of some types of male infertility were hoped (21). In so many studies the reverse effect between sperm parameters and BMI were reported $(11,12,16,18,19,22,23)$.

In Macdonald and colleagues study in New Zealand they created no significant correlation between BMI and semen parameters $(17,24)$. As we know Obesity by increasing estradiol which is produced in peripherals tissues has negative feedback in pituitary gland then causes hypogonadotropin and hypoandrogenism. In recent study a relation between obesity with increasing estradiol level, decreasing testosterone level and decreasing sperm count were seen. Decreasing in sperm count is a known factor in male infertility. In Aggerholm et al study qualification of sperm parameters in infertile men were assessed and lower sperm count concluded in the cases with BMI 25/1- 30 to compare with BMI 20 to 25.Also they saw sperm count reduction with BMI more than 30 . They concluded high BMI had none appropriately accompanied with sex hormone and sperm quality (25-27). In our study increasing BMI accompanied with increasing estradiole level and decreasing in testosterone level and they caused to lower sperm count .We observed the lowest sperms count in the cases with BMI 24$29 \mathrm{~kg} / \mathrm{m}^{2}$ and more than $29 \mathrm{~kg} / \mathrm{m}^{2}$ to compare with BMI 18-24 kg/m². Also in cases with high BMI changes in sperms count and morphology were meaningful. It seems changes in BMI firstly involve morphology of sperm then decreased the count of it. So in comparing all three groups of this study with each other decreasing of morphology was significant.

In Qin and colleagues research, men with a BMI lower than the normal, compared to men with a normal BMI and high BMI. A reduction in sperm quality and sperm count were observed in the cases with BMI lower than normal rate by them, but the sexual hormones could not justify it (28) .In our study increasing of BMI accompanied with decreasing of sperm morphology and sperm count. In fejes and colleagues study the relation between the weight and testosterone estradiole ratio in Oligospermic men was assessed and they were concluded that in men with high BMI the ratio will be decreased. 
International Journal of Engineering Technology and Scientific Innovation

ISSN: 2456-1851

Volume: 06, Issue: 04 "July-August 2021"

In Hafner and Strain teams' study, obesity was finally marked as an effective factor in infertility with spermatogenesis reduction which is caused by the increased levels of estradiole and decreased level of Testosterone .Other hormones involved in the regulation of Sertoli cell function and spermatogenesis, such as FSH/LH ratios, inhibin B and Sex Hormone Binding Globulin levels have all been observed to be decreased in males with increased BMI $(19,22)$.

\section{CONCLUSION}

In present study, obesity has always been accompanied with estradiole increase, Testosterone reduction and decreased sperms count. Therefore, when BMI increase at the same time sperms count and morphology of sperm decrease and it can be concluded that with weight control, some infertility reasons in men can be avoided. Finally we observed the most fertility in men with normal BMI compare to the other. Our study however provided useful information about some reason of male factor infertility that can be avoided easily with changes in life style and overweight.

\section{ACKNOWLEDGEMENT}

The authors wish to express sincere gratitude and appreciation to their colleges in Mirzakoochak- khan infertility clinic.

\section{REFERENCES}

1. $\quad$ Sperof L, Marc A. 6th Ed. Philadelphia; Robert-D. Clinical gyn end \& infertility. 2012.

2. Guo $\mathrm{D}, \mathrm{Wu} \mathrm{W}$, Tang $\mathrm{Q}$, et al. The impact of BMI on sperm parameters and the metabolite changes of seminal plasma concomitantly. Oncotarget 2017;8(30):48619-48634.

3. Kocełak P, Chudek J, Naworska B, et al. Psychological disturbances and quality of life in obese and infertile women and men. Int J Endocrinol 2012;2012:236217.

4. Jensen T, Andersson A, Jorgensen N, Andersen A, Carlsen E, Petersen JH, $\underline{\text { Skakkebaek, }}$ NE. Body mass index in relation to semen quality and reproductive hormones among 1558 danish men. Fertile sterility 2004. 82, 863-870.

5. Catalano, P., 2007. Management of obesity in pregnancy. Obstet Gynecol. 109, 419 -433.

6. Palmer N O, Bakos H W, Fullston, T, Lane, M., 2012 .Impact of obesity on male fertility, sperm function and molecular composition. Spermatogenesis. 1, 253-263.

7. Kasturi, S., Tannir, J, Brannigan, R E. The metabolic syndrome and male infertility. Journal And2008; 29, 251-259.

8. Tsai, E S., Matsumoto, A M., Fujimoto, W Y., Boyko, E J.,.Assosiation of bioavailable, free and total testosterone with insulin resistance : influence of sex hormone-binding globulin and body fat . Diabetes care. 2004; 27, 861-8.

9. Kort, H I., Massey, J B., Elsner, C W., Mitchell-Leef, D., Shapiro, D B., Witt, M A., 
International Journal of Engineering Technology and Scientific Innovation

ISSN: 2456-1851

Volume: 06, Issue: 04 "July-August 2021"

Roudebush, WE., 2006. Impact of body mass index values on sperm quantity and quality. J of And. 27, 450-2.

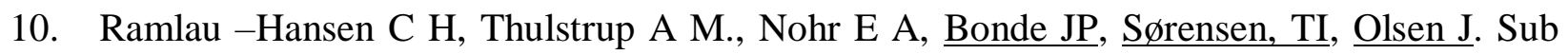
fecundity in overweight and obese couples .human repro. 2007; 22(6): 1634-7.

11. Magnusdottie E V, Thorsteinsson T, Thoresteinsdottir S, Hemisdottir M. Persistent Organochlorines, sedentary occupation, Obesity and Human male sub fertility. Human rep 2005. 20, $208-215$.

12. Hammoud AO, Wilde, N, Gibson M, Parks A, Carrell DT, Meikle, AW. Male obesity and alteration in sperm parameters. Fret Ster 2008. 90, 2222-5.

13. Seftel A. Mal hypogonadism. Part 2: Etiology, pathophysiology anddiagnosis. Int J Impot Research 2006. 18, 223- 8.

14. Chung, W S., Sohn, J H., Park, Y Y. Is obesity underlying factor in erectile dysfunction? European urology. 1999; 36, 68 - 70.

15. Meeker JD, Godfrey L, Hauser R. Relationships between serum hormone levels semen quality among men from an infertility clinic. J And 2007. 28, 397-406.

16. Giagulli VA, Kaufman JM, Vermeulen A. Pathogensis of the decreased androgen levels in obese men. J ClinEndoceinolMetab 1994; 79, 997-1000.

17. Macdonald AA.Stewart AW, Farquhar CM. Body mass index in relation to semen quality and reproductive hormones in New Zealand men: a cross-sectional study in fertility clinics. Hum Reprod2013. 28, 3178-87.

18. Akingbemi B T. Estrogen regulation of testicular function. Reproductive biology end 2005; 3,51 .

19. Strain, G W., Zumoff, B., kream, J., Strain, JJ, Deucher, R, Rosenfeld, RS, et al. Mild hypogonadotropic hypogonadism in obese men. Met 1982: 31, 871-5.

20. Wass P, Waldenstron U, RossnerS, HellbergD. An Android body fat distribution in females impairs the pregnancy rate of in-vitro fertilization - embryo transfer. Human rep 1997;12, 2057- 2060 .

21. GopalkrishnanK, Padwal V, Meherji PK, Gokral JS, Shah R, Juneja HS. Poor quality of sperm as it affect repeated early pregnancy loss . Arch Andro2000:45, 111-117.

22. Bieniek JM., Kashanian JA, Deibert CM, Grober ED, Lo KC,Brannigan RE, et al. Influence of increasing body mass index on semen and reproductive hormonal parameters in a multi-institutional cohort of subfertile men. FertilSteril 2016; 106, 1070-1075.

23. Alshahrani S, Ahmed AF,Gabr, AH, Abalhassan, M, Ahmad, G. The impact of body mass index on semen parameters in infertile men. Andrologia2016;48,1125-1129.

24. Thomsen, L., Humaidan, P., Bungum, L., Bungum, M., 2014. The impact of male overweight on semen quality and outcome of assisted reproduction. Asian J Androl.16, 749-54. 
25. Sallmen M, Sandler DP., Hoppin Ja, Blair A, Baird DD. Reduced fertility among overweight and obese men. Epi 2006;17, 520-3.

26. Nguyen R, Wilcox A,Skjaern R, Baird DD. Men's body mass index and infertility.HumReprod 2007;22, 2488-93.

27. Aggerholm AS, Thulstrup AM, Toft G., Ramlau-Hansen C.H., Bonde J.P.Is overweight a risk factor for redused semen quality and altered serum sex hormone profile? Fertile steril. 2008; 90 (3): 619-626.

28. Qin DD, Yuan W, Zhou WJ, Cui YQ, Wu JQ, Gao ES. Do reproductive hormones explain the association between body mass index and semen quality?. Asian J Androl. 2007; 9(6): 827-834.

29. Fejes I, Koloszar S, Zavaczki Z, Daru J,Szöllösi J, Pál A. Effect of body weight on testosterone / estradiol ratio in oligozoospermic patients. Arch Androl ;52(2):97-102.

30. Mokdad AH, Serdula MK, Dietz WH, Bowman BA, Marks JS, Koplan JP. The Spread of the Obesity Epidemic in the United States, 1991-1998. JAMA 1999; 282(16):1519-1522.

31. Hedley AA, Ogden CL, Johnson CL, Carroll MD, Curtin LR, Flegal KM. Prevalence of Overweight and Obesity Among US Children, Adolescents, and Adults, 1999-2002. JAMA 2004;291(23):2847-2850. 